\title{
LXIII. On an extension of Carnot's theorem
}

\section{J. Parker B.A.}

To cite this article: J. Parker B.A. (1888) LXIII. On an extension of Carnot's theorem, Philosophical Magazine Series 5, 25:157, 512-514, DOI: 10.1080/14786448808628221

To link to this article: http://dx.doi.org/10.1080/14786448808628221

$$
\text { 册 Published online: } 29 \text { Apr } 2009 .
$$

Submit your article to this journal

LII Article views: 3

Q View related articles $\asymp$ 
an exaggerated degree in measuring the temperature of a couple of which one element is steel, by means of a second couple placed inside an enclosure side by side with the steel couple. The accession of heat in the enclosure due to the reglow of the steel in the thermoelectric couple is not enough to produce an effect on the thermometric couple.

There is another peculiarity in the thermoelectric properties of steel, to which Mr. Tomlinson refers (Phil. Mag. Jan. 1888). A piece of steel wire is connected up with a galvanometer, and is heated by a flame at a point remote from the galvanometer connexions. There are no signs of a resultant E.M.F. in the circuit, even when the flame is moved, until 'darkening' has occurred. Then, however, if the flame be moved along the wire so that reglow takes place behind it in the cooling part, and darkening in front in the part being heated, an E.M.F. results, and persists only so long as the flame is kept moving.

In proving the rise of temperature throughout the mass of steel during recalescence, I have shown that the temperature of recalescence is different from that of darkening, the latter being higher. This difference of temperature of what may be regarded as the junctions of the hot altered steel with the cold steel on each side, determines the E.M.F. in the circuit.

LXIII. Un an Extension of Carnot's Theorem. By J. PARKER, B.A., late Scholar of St. John's College, Cambridge*.

$\mathrm{T}^{\mathrm{T}}$ is well known that no engine can be more efficient in 1 transforming heat into mechanical work than Carnot's reversible engine, and that all reversible engines are of the same efficiency. It is also generally believed, without, however, being proved, that no irreversible engine can be so efficient as Carnot's. This is the point we propose to examine.

One of the principal conditions imposed on a system subjected to a reversible operation is that, at every instant, the system is in mechanical and thermal equilibrium. This condition, however, also belongs to a certain class of irreversible processes, as we shall presently see.

Thus, when a saturated solution of sodium chloride is heated with an excess of the salt, the salt is dissolved; but if the temperature is again reduced, the solution deposits, not the anhydrous salt, but crystals of the bihydrate. Again, a salt is neutral to pure ice at the freezing temperature of its cryohydrate; and if heat is slowly imparted, the liquid cryohydrate

* Communicated by the Author. 
will be formed at this constant temperature. The system is in mechanical and thermal equilibrium thronghout the process; but the process is not reversible, for if heat is slowly abstracted from the liquid cryohydrate, it is not dissociated-it is simply frozen.

We define an "equilibrium path" to be a path at every point of which the system under consideration is in equilibrium, which may be either stable or unstable, provided, of course, that the equilibrium is not broken at any point of the path.

A reversible path is always an "equilibrium path," but an "equilibrium path" is not necessarily reversible, as we have already seen. All the irreversible equilibrium paths I have noticed correspond to an absorption of heat-that is, an increase of entropy.

Now it is well known that in a complete cycle the energy dissipated $=-t_{0} \int \frac{d q}{t}$, where $d q$ denotes a quantity of heat absorbed, and $t_{0}$ is the temperature of the refrigerator. Clausius has shown that this quantity cannot be negative, and that when the cycle is reversible it is equal to zero. It is then generally assumed that in all irreversible cycles the energy dissipated has a positive value.

The study of Solubilities has compelled me to adopt a different view. I have been led to conclude that in any irreversible equilibrium-cycle the energy dissipated is zero, but that in all other irreversible cycles the energy dissipated has a positive value. Any irreversible equilibrium-engine is, then, as efficient as Carnot's perfectly reversible engine, and all other irreversible engines are loss efficient than Carnot's.

We have already seen that $\int \frac{d q}{t}=0$ for any equilibriumcycle. Suppose, then, that a system travels from one position $A$ to another position $B$ by an irreversible equilibrium path, and let the cycle be completed by the reversible path BCA. It has been shown by Clausius that, for the reversible path $\mathrm{BCA}$,

$$
\mathrm{S}_{\mathrm{A}}-\mathrm{S}_{\mathrm{B}}-\int_{\mathrm{B}}^{\mathrm{A}} \frac{d q}{t}=0
$$

where $S_{\mathbf{A}}$ is the entropy of the system in the position $A$, and $\mathrm{S}^{\mathrm{B}}$ the entropy in the position B. But $\int \frac{d q}{t}=0$ for the complete cycle: hence, for the irreversible equilibrium path $A B$, 
we have

$$
\mathbf{S}_{\mathbf{B}}-\mathrm{S}_{\mathbf{A}}-\int_{\mathbf{A}}^{\mathbf{B}} \frac{d q}{t}=0 .
$$

Thus; if the system can pass from the position $A$ to the position $B$ by several irreversible equilibrium paths, then $\int_{\mathbf{A}}^{B} \frac{d q}{t}$
has the same value for all the paths.

Again, when the temperature is constant throughout the modification, the heat absorbed will be

$$
t\left(\mathrm{~S}_{\mathrm{B}}-\mathrm{S}_{\mathrm{A}}\right) \text {. }
$$

An example of this will be found in equation (4), page 408 (May 1888).

In particular, consider the formation of unit weight of a liquid cryohydrate under a pressure equal to the pressure of the saturated vapour of ice. The cycle may be completed by the following operations, performed at constant temperature and pressure :-

(1) Let the cryohydrate be dissociated by evaporation into the saturated vapour of ice and the anhydrous salt or a hydrate. In the latter case, the cryohydrate is supposed to have been formed from the hydrate and ice.

(2) Let the aqueous vapour be separated from the salt, and then condensed into the solid state.

Since the pressure is constant throughout the cycle, the total work done and heat absorbed are both zero.

But if $S$ be the entropy of the cryohydrate, and $S_{1}$ the sum of the entropies of the salt and ice of which it is composed, the heat absorbed in the reversible parts of the cycle will be

$$
t \cdot\left(\mathrm{S}_{1}-\mathrm{S}\right) \text {. }
$$

Hence the heat absorbed in the formation of the cryohydrate -an irreversible process-will be

$$
\mathrm{Q}=t .\left(\mathrm{S}-\mathrm{S}_{1}\right) \text {. }
$$

\section{Notices respecting New Books.}

Transactions of the Edinburgh Geological Society, Vol. V., Part $\amalg$. (Pp. 335-483.) Edinburgh, 1887.

$\mathrm{A}^{\mathrm{N}}$ interesting inaugural address by $\mathrm{Mr}$. Ralph Richardson, A treating of the discoveries of Fossil Mammalia in Scotland, with a map and lists of the places at which the individual species have been found, conmences this number of the 'Transactions.' Following this, Mr. John Henderson treats of the Sands and Gravels of Musselburgh and Stockbridge, containing remains of 